\title{
A qualitative optimization technique for biophysical neuron models with many parameters
}

\author{
Robert Clewley ${ }^{1,2^{*}}$, Mirza Dobric ${ }^{2}$ \\ From Nineteenth Annual Computational Neuroscience Meeting: CNS*2010 \\ San Antonio, TX, USA. 24-30 July 2010
}

We present a novel computational technique that enables more efficient optimization of qualitative features in biophysical neural models. We extend the idea of multiple objective optimization for a single comparison modality (such as comparison of individual voltage traces) [1] into multiple modalities. For instance, features may be defined in terms of measurements from different experimental scenarios, and might include not only action potential spike shape characteristics (Cf. [1,2]) but also complex features such as the frequency response curve, and phase response curve (PRC). Multiple fuzzy feature modalities provide additional ways to distinguish solutions that might otherwise appear similarly fit in the restrictive view of a single modality and with crisp measures of fitness. An ill-posed optimization problem with many local minima typically arises from relative insensitivities of some parameters to features in a single modality, or parameter co-variation/modulation [2].

We use an implementation in the PyDSTool software [3] to demonstrate how the multi-modal approach can be prepared and embedded in conventional gradientbased or global optimization algorithms. Among other applications, we discuss the transformation over 25 model parameters of a Hodgkin-Huxley neuron model with a Type I PRC [4] to a Type II PRC, using a goal PRC shape and other periodic trajectory statistics as fuzzy objective modalities.

\footnotetext{
Author details

${ }^{1}$ Neuroscience Institute, Georgia State University, Atlanta, GA 30303, USA. ${ }^{2}$ Department of Mathematics and Statistics, Georgia State University, Atlanta, GA 30303, USA.
}

\footnotetext{
* Correspondence: rclewley@gsu.edu

${ }^{1}$ Neuroscience Institute, Georgia State University, Atlanta, GA 30303, USA
}

Published: 20 July 2010

\section{References}

1. Druckmann S, Banitt Y, Gidon A, Schurmann F, Markram H, Segev I: A Novel Multiple Objective Optimization Framework for Constraining Conductance-Based Neuron Models by Experimental Data. Frontiers in Neuroscience 2007, 1(1):7-18.

2. Achard P, De Schutter E: Complex Parameter Landscape for a Complex Neuron Model. PLoS Comput Biol 2006, 2(7):e94.

3. Clewley RH, Sherwood WE, Lamar MD, Guckenheimer JM: PyDSTool: a software environment for dynamical systems modeling. 2004 [http:// pydstool.sourceforge.net].

4. Rinzel J, Ermentrout GB: Analysis of neural excitability and oscillations. Methods in Neural Modeling MIT Press, CambridgeC Kock and I Segev 1989, 135-169.

doi:10.1186/1471-2202-11-S1-P39

Cite this article as: Clewley and Dobric: A qualitative optimization technique for biophysical neuron models with many parameters. $B M C$ Neuroscience 2010 11(Suppl 1):P39.
Submit your next manuscript to BioMed Central and take full advantage of:

- Convenient online submission

- Thorough peer review

- No space constraints or color figure charges

- Immediate publication on acceptance

- Inclusion in PubMed, CAS, Scopus and Google Scholar

- Research which is freely available for redistribution

Submit your manuscript at www.biomedcentral.com/submit
C Biomed Central 